\title{
ÉPOCAS DE SEMEADURA DO ARROZ DE SEQUEIRO NA REGIÃO DE TANGARÁ DA SERRA
}

\author{
William Fenner ${ }^{1}$, Rivanildo Dallacort ${ }^{2}$, Adalberto Santi $^{3}$, Ricardo Shigueru Okumura ${ }^{4}$, Rafael Cesar Tieppo ${ }^{5}$
}

\begin{abstract}
RESUMO
O Estado de Mato Grosso apresenta irregularidades no regime pluvial, sendo necessário um estudo climático buscando indicar as melhores épocas de cultivo com o menor risco de ocorrência de déficit hidrico. Com isso, este trabalho objetivou identificar as melhores épocas de semeadura com menor risco climático para o cultivo de arroz de terras altas, por meio de análises térmicas e hídricas dos últimos cinco anos agrícola para o município de Tangará da Serra, MT. Utilizaram-se dados de temperatura e precipitação dos últimos cinco anos (2007/2008 a 2011/2012) disponibilizados pelo Instituto Nacional de Meteorologia (INMET). As épocas de menor risco climático foram determinadas a partir da simulação do desenvolvimento da cultura, por meio do cálculo da soma térmica e por meio do cálculo do balanço hídrico proposto por Thornthwaite e Mather, comparando-se com as necessidades hídricas para as fases de desenvolvimento. A duração das fases da cultura foram de 50 dias para E/R1, 78 dias em E/R4 e 103 dias para E/MC. Semeaduras mais tardias, como as relativas às épocas 5 (15 de dezembro) e 6 (31 de dezembro), aumentam a duração total do ciclo, bem como o número de dias para a floração. As épocas mais favoráveis ao cultivo foram as épocas 5 e 6 (15 de dezembro e 31 de dezembro, respectivamente).
\end{abstract}

Palavras-chave: balanço hídrico, Oryza sativa, precipitação, soma térmica, temperatura

\section{ABSTRACT \\ SOWING TIMES OF UPLAND RICE IN THE REGION OF THE TANGARÁ DA SERRA}

The Mato Grosso state shows irregularities in rainfall patterns, requiring a climate study seeking to establish the optimum planting dates with the lowest risk of hydric deficit. Therefore, this study aimed to identify the best sowing times with less risk climate for growing of upland rice through hydro and thermal analysis of the last five crop years for the town of Tangará da Serra, MT. We used data of temperature and precipitation of the last five years (2007/2008 a 2011/2012) provided by the Instituto Nacional de Meteorologia (INMET). The times less climate risk were determined from the simulation of crop development by calculating the degree-day and by calculating the water balance proposed by Thornthwaite and Mather, comparing with the water needs for the development stages. The duration of the phases of the culture was to E/R1 50 days, 78 days and 103 days for E/R4 E/MC. Later sowings as five times (December 15) and six (December 31) increase the total cycle time, as well as the number of days to flowering. The sowing dates were more favorable to the cultivation was 5 and 6 (December 15 and December 31, respectively).

Keywords: Oryza sativa, precipitation, temperature, thermal sum, water balance

\section{Recebido para publicação em 04/03/2013. Aprovado em 20/08/2013.}

1 - Eng. Agrônomo, Pós-graduando em Ambiente e Sistemas de Prod. Agrícola - PPGASP/UNEMAT, fennerwilliam@gmail.com

2 - Engenheiro Agrícola, Professor da UNEMAT/Tangará da Serra - MT, rivanildo@unemat.br

3 - Engenheiro Agrônomo, Professor da UNEMAT/Tangará da Serra - MT, adalbertosanti@unemat.br

4 - Engenheiro Agrônomo, Professor da UFRA/Belém - PA, ricardo_okumura@hotmail.com

5 - Engenheiro Agrícola, Professor da UNEMAT/Tangará da Serra - MT, tiepporc@usp.br 


\section{INTRODUÇ̃̃O}

No Brasil, as principais regiões produtoras de arroz são a Sul, Nordeste e Centro Oeste com 75,2, 8,7 e $7,5 \%$ da produção nacional, respectivamente. No ano agrícola de 2010/11 foram cultivados mais de 2,7 milhões de hectares, com produção acima de 13 milhões de toneladas de arroz em casca. Regionalmente, o Estado de Mato Grosso responde por $4,9 \%$ da produção nacional, baseada no cultivo de arroz de terras altas com produtividade média de 3.186 $\mathrm{kg} \mathrm{ha}^{-1}$, valor este abaixo do maior produtor brasileiro, o Rio Grande do Sul, com $7.642 \mathrm{~kg} \mathrm{ha}^{-1}$ (IBGE, 2012).

No Estado de Mato Grosso, a tecnologia empregada no cultivo do arroz de sequeiro é inferior à utilizada em sistemas irrigados, em que se expõe a cultura a inúmeras variações climáticas. Uma ferramenta utilizada para minimizar estes efeitos sobre a mesma é o balanço hídrico (HEINEMANN, 2010; WREGE et al., 2001). O balanço hídrico é uma ferramenta muito importante na realização do zoneamento agroclimático, tendo o objetivo de minimizar quebras de safra, coincidindo os períodos de maior exigência da cultura com os períodos de maior disponibilidade hídrica e menor risco de estiagens (LORENÇONI et al., 2010; NUNES et al., 2007; SILVA; ASSAD, 2001).

Thornthwaite e Mather (1955) descrevem o balanço hídrico como um cálculo utilizado para estimar a quantidade de água no solo, fornecendo informações da disponibilidade hídrica do solo por meio da relação das entradas (precipitação e irrigação) e saídas de água (evapotranspiração, drenagem profunda e escoamento superficial) em um determinado período de tempo (BISCARO, 2007; PEREIRA, 2005).

O regime pluvial é caracterizado pela quantidade e distribuição das chuvas durante o ciclo da cultura, sendo estes os fatores limitantes a produção quando não são utilizados sistemas de irrigação, uma vez que às irregularidades da distribuição das chuvas resultam no aumento do risco climático para o cultivo (HEINEMANN; STONE, 2009; MARINI et al., 2012; PIRES, 2008).

Segundo Stone (1982), quando a cultura do arroz é submetida a condições de estresse hídrico, a mesma apresenta redução no número de grãos por panícula, redução na altura de planta, no índice de colheita, na massa dos grãos e aumento no número de grãos vazios.

Yoshida e Parao (1976) ressaltam que a intensidade dos efeitos negativos do estresse hídrico depende da idade da planta, caso ocorra na fase vegetativa ocasiona redução no número de perfilhos, diminuição da área foliar e altura de planta e, com isso, há uma redução no número de panículas por $\mathrm{m}^{2}$, número e massa de grãos cheios, o que afeta diretamente a produtividade. Por sua vez, diversos autores consideram os danos ocasionados na fase reprodutiva como os mais severos e irreversíveis (HEINEMANN; STONE, 2009; RODRIGUES; SORATTO; ARF, 2004; SILVA et al., 2009; YOSHIDA; PARAO, 1976).

Diante do exposto, este trabalho objetivou identificar as melhores épocas de semeadura para o cultivo de arroz de sequeiro, embasado em análises térmicas e hídricas dos últimos cinco anos para o município de Tangará da Serra, MT.

\section{MATERIAL E MÉTODOS}

O presente trabalho foi realizado no Laboratório de Agrometeorologia do Campus da Universidade do Estado de Mato Grosso, localizada no município de Tangará da Serra, MT.

Os dados de temperatura e precipitação dos cinco últimos anos agrícolas (2007/2008 a 2011/2012) do município de Tangará da Serra, utilizados na realização do trabalho, foram disponibilizados pelo Instituto Nacional de Meteorologia (INMET), que possui uma estação automática localizada na latitude $14^{\circ} 65^{\prime} 00^{\prime}$ ' S, longitude $57^{\circ} 43^{\prime} 15^{\prime}$ ' W e altitude de 321,5 m. Para organização, análise de consistência dos dados e cálculo de médias das temperaturas e precipitação utilizou-se o software computacional CLIMA, descrito por Faria et al. (2003).

As melhores épocas de cultivo do arroz no Estado de Mato Grosso, bem como as épocas de maior risco climático, foram determinadas por meio da utilização dos parâmetros de temperatura descritos por Yoshida (1981), e a partir do cálculo do balanço hídrico proposto por Thornthwaite e Mather (1995).

Para o balanço hídrico diário do solo foram considerados a evapotranspiração de referência e a capacidade de armazenamento de água (CAD) de $100 \mathrm{~mm}$, utilizaram-se dados diários de temperatura e precipitação dos cinco últimos anos, sendo os mesmos inseridos em uma planilha de cálculo do Excel (ROLIM; SENTELHAS; BARBIERI, 1998).

Para o cálculo da soma térmica, consideraram-se as seis principais épocas de semeadura recomendadas para o Estado de Mato Grosso (MAPA, 2011): Época 1: 16 de outubro; Época 2: 1 de novembro; Época 3: 16 de novembro; Época 4: 1 de dezembro; Época 5: 15 de dezembro e Época 6; 31 de dezembro. A determinação da duração do ciclo da cultura foi realizada para cada ano, utilizando-se a quantidade de graus-dia necessária para completar as principais fases fenológicas da cultura (STEINMETZ et al., 
2009). No cálculo, foi utilizado a metodologia descrita por Xue et al. (2004), na qual se considera a soma dos graus-dia acima da temperatura crítica inferior (temperatura base), durante o ciclo da cultura. A temperatura base utilizada para o cálculo foi $10^{\circ} \mathrm{C}$ (LAGO et al., 2009).

$\mathrm{O}$ resultado do balanço hídrico foi comparado com a estimativa de duração do ciclo, realizada por meio da soma térmica, na qual analisa os períodos em que a cultura do arroz necessita de maior disponibilidade hídrica, verificando se houve ocorrência de deficiência ou umidade suficiente para o desenvolvimento da cultura na região, identificando, assim, a melhor época de semeadura.

\section{RESULTADOS E DISCUSSÃO}

Considerando-se a temperatura, a região não apresenta restrições ao cultivo de arroz durante todo o ano, estando a temperatura média anual dentro da faixa ideal $\left(18\right.$ a $\left.35^{\circ} \mathrm{C}\right)$ para o desenvolvimento da cultura segundo Fenner et al. (2011), que, em trabalho de aptidão agroclimática da cultura do arroz de sequeiro para o muncípio de Tangará da Serra - MT, verificaram apenas a restrição hídrica e a presença de veranicos em alguns periodos do ano, fazendo-se necessário realizar a semeadura nas épocas que apresentem menores riscos de ocorrência de deficiência hídrica para a cultura, não sendo a temperatura um fator limitante ao cultivo da cultura na região em estudo.

O ano agrícola de 2009/10 apresentou média pluviométrica acima de $1.000 \mathrm{~mm}$ durante o ciclo da cultura $(1.052,11 \mathrm{~mm})$ seguido por 2010/11; 2007/08; 2011/12 e 2008/09 com 888,26; 864,43; 768,86 e 731,68 mm, respectivamente. Resultados acima dos obtidos por Stone e Silveira (2004), que determinaram quantidade mínima exígida pela cultura do arroz de sequeiro durante todo o seu ciclo entre 600 e $700 \mathrm{~mm}$. Todas as épocas de semeadura nos últimos cinco anos agrícolas apresentaram valores acima do ideal, evidenciando a aptidão da região ao cultivo do arroz de sequeiro (Quadro 1).

As épocas de semeadura 4, 5 e 6 apresentaram médias de precipitação durante todos os períodos analisados acima de $900 \mathrm{~mm}$, enquanto as épocas 1 e 2 apresentaram os menores acumulados, 742,92 e $770 \mathrm{~mm}$, respectivamente. De maneira geral, os anos de 2009/10, 2010/11 e 2011/12 apresentaram os maiores acumulados de precipitação, principalmente nas épocas 4, 5 e 6.

As irregularidades na precipitação pluviométrica corroboram com Heinemann e Stone (2009) e Silva et al. (2009), que, trabalhando com duas cultivares de ciclo curto (Guarani e Soberana) e duas de ciclo médio (Curinga e Primavera) com ensaios sem e com condição de deficiência hídrica no município de Porangatu - GO, observaram efeitos negativos, comprometendo o desenvolvimento da cultura, afetando a qualidade dos grãos e a produtividade do arroz, pela redução do número de panículas e redução da fertilidade das espiguetas.

A média de precipitação para cada época de semeadura variou de $742,92 \mathrm{~mm}$ (época 1) a $953,56 \mathrm{~mm}$ (época 4), e a média geral foi de 861,07 $\mathrm{mm}$. Este valores estão abaixo dos preconizados por Ciiagro (2009), que determinou valor o ótimo próximo a $1.200 \mathrm{~mm}$ durante o ciclo do arroz.

A estimativa de duração total do ciclo da cultura apresentou variação máxima de até 7 dias entre a primeira ( 16 de outubro) e a última ( 31 de dezembro). Entre todas as épocas de semeadura, as que demonstraram as maiores variações na duração do ciclo foram a 5 e 6 ( 15 de dezembro e 31 de dezembro). Para as demais épocas de semeadura, a diferença na duração total do ciclo foi de no máximo 5 dias (época 4), sendo as épocas 1,2 e 3, com variação de 4 dias para a maturação completa (Quadro 2).

Quadro 1. Precipitação acumulada em milímetros durante o ciclo da cultura nas seis épocas de semeadura dos últimos cinco anos agrícolas, no município de Tangará da Serra, MT

\begin{tabular}{lcccccc}
\hline \multirow{2}{*}{ Época de semeadura } & \multicolumn{7}{c}{ Precipitação durante o ciclo (mm) } & \\
\cline { 2 - 7 } & $2007 / 08$ & $2008 / 09$ & $2009 / 10$ & $2010 / 11$ & $2011 / 12$ & Média \\
\hline 1 & 904,0 & 682,2 & 919,8 & 635,0 & 573,6 & 742,92 \\
2 & 947,0 & 661,5 & 925,9 & 676,0 & 639,6 & 770,00 \\
3 & 827,0 & 693,1 & 1083 & 827,2 & 833,4 & 852,74 \\
4 & 827,0 & 833,5 & 1227,5 & 1014,2 & 865,6 & 953,56 \\
5 & 827,6 & 761,3 & 1102,0 & 1065,8 & 888,8 & 929,10 \\
6 & 854,0 & 758,5 & 1054,5 & 1111,4 & 812,2 & 918,12 \\
\hline Média & 864,43 & 731,68 & 1052,11 & 888,26 & 768,86 & 861,07 \\
\hline
\end{tabular}


O número médio de dias para a cultura atingir o estádio de desenvolvimento de diferenciação de primórdio floral foi de 50 dias, com variação entre 47 e 52 dias, enquanto para atingir o estádio de floração plena foram necessários em média 78 dias, em um intervalo de 74 a 81 dias.

$\mathrm{O}$ número de dias para alcançar estas fases aumentou nas épocas de semeadura tardias (dezembro), resultados que corroboram com os obtidos por Streck (2006), que relaciona o aumento da duração do ciclo com a duração do fotoperíodo, uma vez que o arroz é uma planta de dias curtos e, neste período, a cultura é exposta a um maior fotoperíodo, resultando no aumento do número de

Quadro 2. Número de dias e graus dia $\left({ }^{\circ} \mathrm{C}\right)$ acumulados para atingir as fases de: Emergência a diferenciação do primórdio floral (E/R1); Emergência a floração (E/R4); Emergência a maturação completa (E/MC), considerando-se seis épocas de semeadura dos últimos cinco anos agrícolas (2007/2008 a 2011/2012) no município de Tangará da Serra, MT

\begin{tabular}{|c|c|c|c|c|c|c|c|}
\hline \multirow{2}{*}{$\begin{array}{l}\text { Época de } \\
\text { semeadura }\end{array}$} & \multirow{2}{*}{ Ano } & \multicolumn{6}{|c|}{ Número total de dias e graus-dia acumulado (GDA) para atingir a mudança de fase fenológica } \\
\hline & & E/R1 & GDA & $\mathrm{E} / \mathrm{R} 4$ & GDA & $\mathrm{E} / \mathrm{MC}$ & GDA \\
\hline \multirow{5}{*}{$\begin{array}{l}\text { Época } 1 \\
(16 / 10)\end{array}$} & $2007 / 08$ & 48 & 734,6 & 76 & 1149,1 & 101 & 1481,5 \\
\hline & $2008 / 09$ & 47 & 739,5 & 74 & 1142,3 & 98 & 1508,1 \\
\hline & $2009 / 10$ & 47 & 743,2 & 74 & 1136 & 99 & 1504,7 \\
\hline & $2010 / 11$ & 49 & 735,1 & 76 & 1136,3 & 102 & 1502,7 \\
\hline & $2011 / 12$ & 47 & 733,1 & 75 & 1141,4 & 102 & 1513,9 \\
\hline \multirow{5}{*}{$\begin{array}{c}\text { Época } 2 \\
(01 / 11)\end{array}$} & $2007 / 08$ & 49 & 735,7 & 77 & 1144,2 & 104 & 1506,5 \\
\hline & $2008 / 09$ & 48 & 741,5 & 75 & 1136,3 & 102 & 1512,1 \\
\hline & $2009 / 10$ & 49 & 740,6 & 76 & 1139,3 & 100 & 1506,6 \\
\hline & $2010 / 11$ & 50 & 733,8 & 78 & 1142,2 & 104 & 1507,5 \\
\hline & $2011 / 12$ & 48 & 735,2 & 76 & 1135 & 102 & 1512,1 \\
\hline \multirow{5}{*}{$\begin{array}{c}\text { Época } 3 \\
(16 / 11)\end{array}$} & $2007 / 08$ & 49 & 740,5 & 78 & 1144,1 & 103 & 1504,3 \\
\hline & $2008 / 09$ & 49 & 741,7 & 75 & 1135,1 & 100 & 1504,3 \\
\hline & $2009 / 10$ & 49 & 739,2 & 76 & 1138,5 & 100 & 1501,6 \\
\hline & $2010 / 11$ & 50 & 735,5 & 78 & 1136,4 & 104 & 1500,9 \\
\hline & $2011 / 12$ & 49 & 734,2 & 78 & 1159,5 & 103 & 1503,9 \\
\hline \multirow{5}{*}{$\begin{array}{l}\text { Época } 4 \\
(01 / 12)\end{array}$} & $2007 / 08$ & 50 & 731,3 & 79 & 1141,6 & 106 & 1512,1 \\
\hline & $2008 / 09$ & 48 & 729 & 76 & 1142,9 & 101 & 1510,8 \\
\hline & $2009 / 10$ & 50 & 731,1 & 77 & 1135,8 & 101 & 1512,1 \\
\hline & $2010 / 11$ & 50 & 731,1 & 79 & 1140,2 & 105 & 1503,6 \\
\hline & $2011 / 12$ & 51 & 740,8 & 79 & 1141,4 & 105 & 1511,3 \\
\hline \multirow{5}{*}{$\begin{array}{c}\text { Época } 5 \\
(15 / 12)\end{array}$} & $2007 / 08$ & 51 & 730 & 80 & 1144,7 & 106 & 1512,4 \\
\hline & $2008 / 09$ & 49 & 742,4 & 76 & 1135,3 & 101 & 1500,7 \\
\hline & $2009 / 10$ & 50 & 739,5 & 76 & 1138,1 & 99 & 1504,1 \\
\hline & $2010 / 11$ & 51 & 731,9 & 81 & 1143,9 & 106 & 1502,1 \\
\hline & $2011 / 12$ & 52 & 755,2 & 80 & 1139,5 & 106 & 1508,7 \\
\hline \multirow{5}{*}{$\begin{array}{c}\text { Época } 6 \\
(31 / 12)\end{array}$} & $2007 / 08$ & 52 & 739 & 81 & 1140,5 & 107 & 1506,7 \\
\hline & $2008 / 09$ & 49 & 738,2 & 76 & 1136,6 & 102 & 1509,8 \\
\hline & $2009 / 10$ & 50 & 742,3 & 75 & 1139,4 & 101 & 1505,6 \\
\hline & $2010 / 11$ & 52 & 734,9 & 81 & 1144,5 & 106 & 1508,1 \\
\hline & $2011 / 12$ & 51 & 728,9 & 80 & 1141,7 & 105 & 1508 \\
\hline
\end{tabular}


dias para mudança de fase fenológica.

A média da soma térmica acumulada para a mudança de estádios de desenvolvimento da cultura do arroz, dos cinco últimos anos agrícolas foi de $736,9,1140,7$ e $1506{ }^{\circ} \mathrm{C}$ acumulados paras as fases de $\mathrm{E} / \mathrm{R} 1, \mathrm{E} / \mathrm{R} 4$ e $\mathrm{E} / \mathrm{MC}$, respectivamente. Resultados estes que corroboram com os obtidos por Steinmetz et al. (2009), que verificaram em trabalhos com cultivares de ciclo precoce no Rio
Grande do Sul, médias de 728,1135 e $1445^{\circ} \mathrm{C}$ para os estádios de desenvolvimento E/R1, E/R4 E E/ $\mathrm{MC}$, respectivamente.

A cultura apresentou duração total média do ciclo de 103 dias durante o período analisado, o que expõe a cultura a um menor risco de ocorrência de déficit hídrico, pois nestes períodos são registrados valores satisfatórios ao cultivo com este intervalo, em torno de 110 dias. Resultados semelhantes
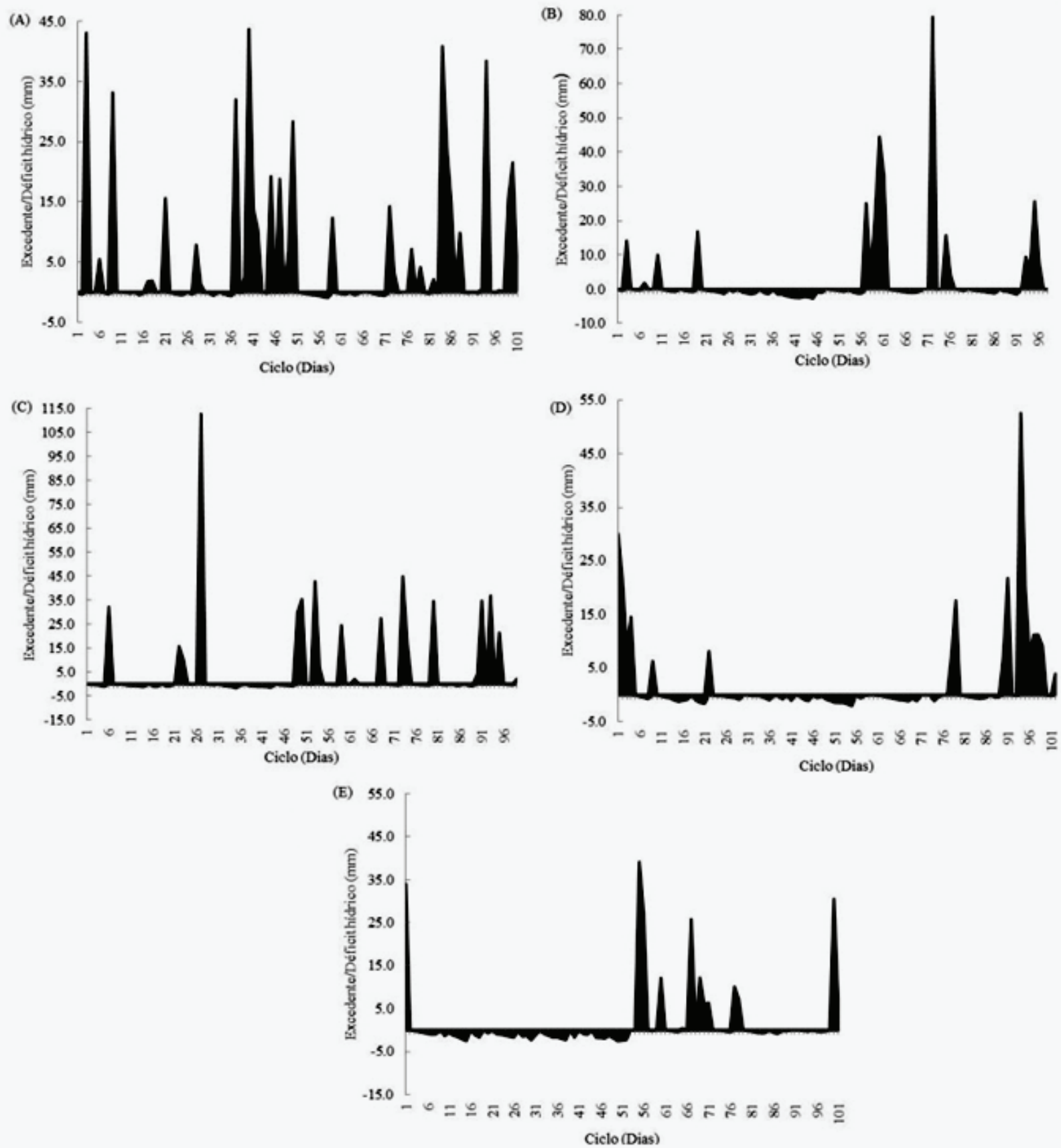

Figura 1. Balanço hídrico diário do município de Tangará da Serra - MT, dos anos agrícolas 2007/08 (A), 2008/09 (B), 2009/10 (C), 2010/11 (D) 2011/12 (E) na primeira época de semeadura (16 de outubro). 
foram obtidos por Silva e Assad (2001), onde, trabalhando com zoneamento de risco climático no Estado de Mato Grosso, verificaram que para semeadura de 1 a 10 de novembro, $70 \%$ das regiões do Estado apresentam condições de baixo risco climático ao cultivo do arroz de sequeiro.

Na época de semeadura 1, apenas o ano agrícola de 2011/12 apresentou déficit hídrico para o período de emergência, compreendido entre 4 a 6 dias após a semeadura. Nos demais anos, a época de semeadura 1 se mostrou favorável à emergência da cultura (Figura 1).

$\mathrm{Na}$ época de semeadura 1, observa-se déficit hídrico nas fases de desenvolvimento mais importantes da cultura do arroz, que são a de diferenciação do primórdio floral e enchimento de grãos (HEINEMANN; STONE, 2009), que compreende dos 50 aos 90 dias após a semeadura, uma vez que, nesta fase, ocorre a translocação de fotoassimilados para a formação e crescimento da panícula, que é bastante prejudicada pela ocorrência de déficits hídricos (LAGO et al., 2009).
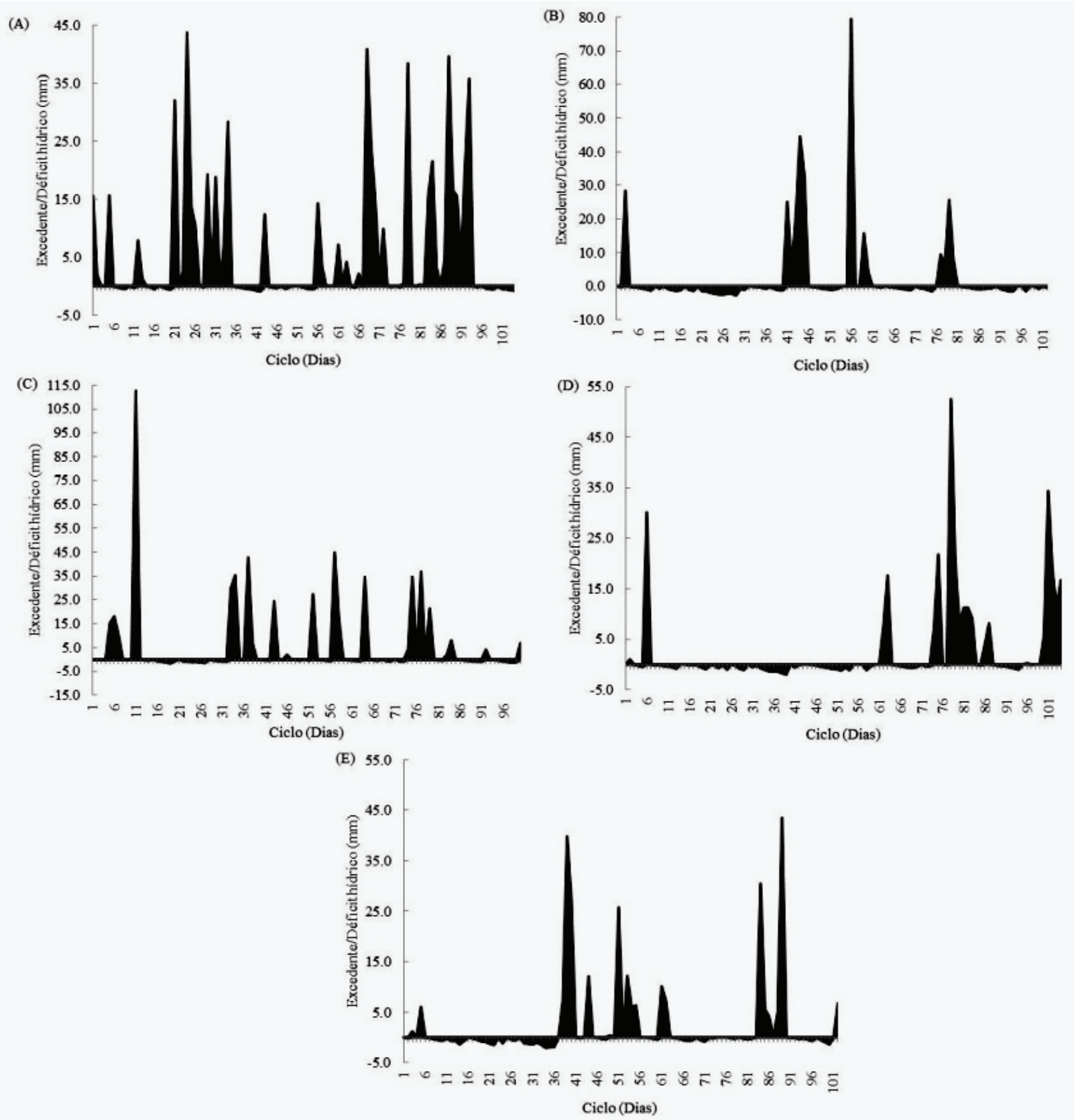

Figura 2. Balanço hídrico diário do município de Tangará da Serra - MT, dos anos agrícolas 2007/08 (A), 2008/09 (B), 2009/10 (C), 2010/11 (D) 2011/12 (E) na segunda época de semeadura (1 de novembro). 

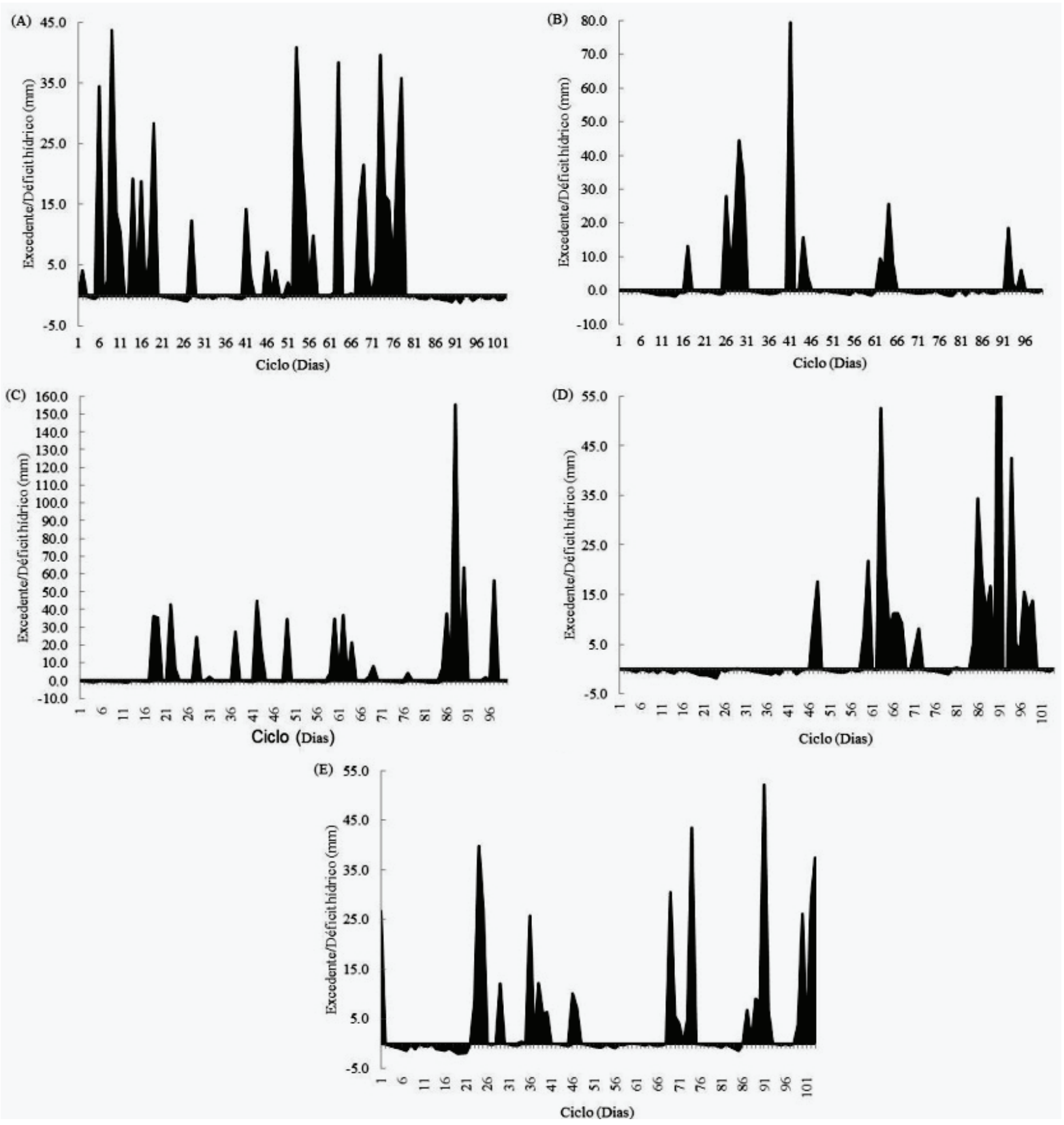

Figura 3. Balanço hídrico diário do município de Tangará da Serra - MT, dos anos agrícolas 2007/08 (A), 2008/09 (B), 2009/10 (C), 2010/11 (D) 2011/12 (E) na terceira época de semeadura (16 de novembro).

De acordo com Brunini et al. (1981) e Carvalho Junior (1987), tais prejuízos são maiores neste período em decorrência da exigência hídrica da planta diferir conforme os estádios fenológicos do arroz, que apresenta consumo hídrico total de $30 \%$ durante a fase vegetativa, $55 \%$ durante a reprodutiva e $15 \%$ na fase de maturação.

Segundo Crusciol et al. (2003), a ocorrência de deficiência hídrica até o período de florescimento da cultura, como as observadas em diversas épocas neste trabalho, proporciona a redução da matéria seca, o que influência negativamente a produção de grãos. Por sua vez, os mesmos autores ressaltam que o manejo adequado da adubação, em conjunto com um sistema de irrigação, pode incrementar em até $40 \%$ a produtividade média da cultura, uma vez que a deficiência hídrica ocorrida durante a meiose da célula-mãe do grão de pólen, que ocorre no período que antecede a fase de florescimento, ocasiona a redução da fertilidade das espiguetas, 
assim como aumenta a duração do ciclo total da cultura (RODRIGUES et al., 2004).

Com exceção da época de semeadura 1, todas as outras apresentaram déficit hídrico para as fases de germinação/emergência e diferenciação do primórdio floral (Figura 2). Os maiores períodos de deficiência hídrica são observados na fase vegetativa, período compreendido da emergência à aproximadamente 50 dias.
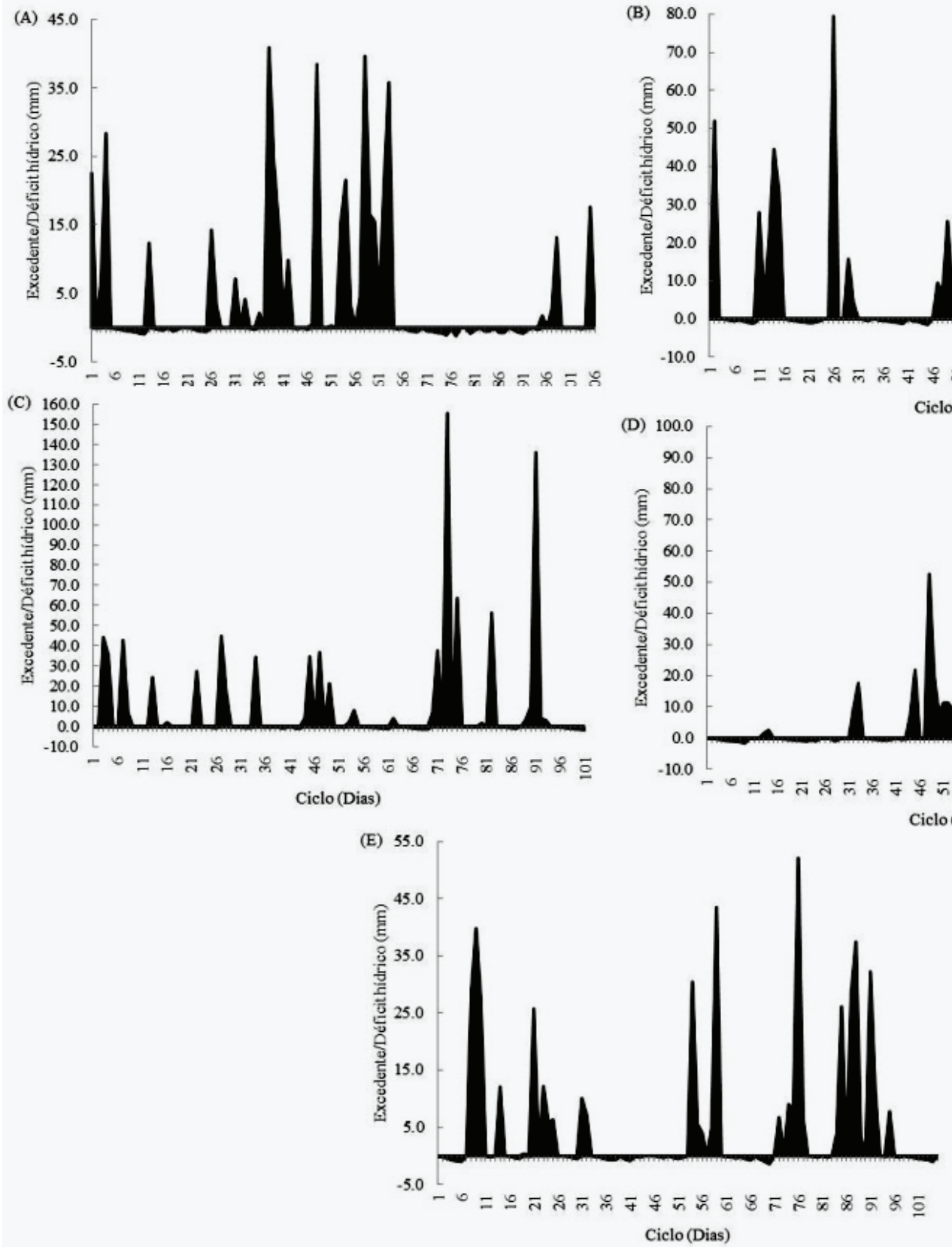

Os anos agrícolas de 2009/10 e 2010/11 apresentaram períodos de déficit hídrico nas fases de emergência e diferenciação do primórdio floral e germinação/emergência, respectivamente (Figura 3). A ocorrência de deficiência hídrica neste período causa significativos prejuízos ao desenvolvimento da cultura, mas sua intensidade é relacionada a outros fatores que irão caracterizar a intensidade dos danos à cultura. Os efeitos destes curtos períodos de
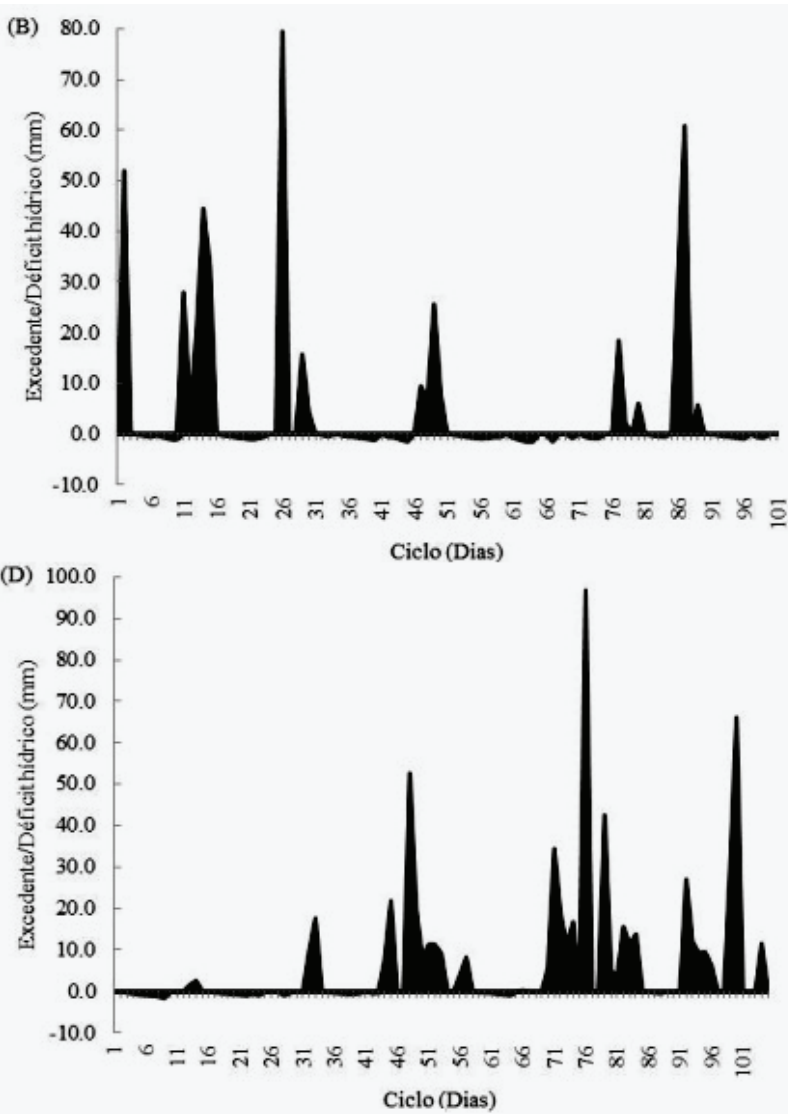
Ciclo(Dias)

Figura 4. Balanço hídrico diário do município de Tangará da Serra - MT, dos anos agrícolas 2007/08 (A), 2008/09 (B), 2009/10 (C), 2010/11 (D) 2011/12 (E) na quarta época de semeadura (1 de dezembro). 
deficiência hídrica sobre o desenvolvimento do arroz são dependentes de uma série de fatores relacionados, por exemplo, ao tipo de solo, tais como o teor de argila, compactação, macro e microporosidade, presença de cobertura vegetal e tipo de preparo do solo (convencional ou sistema plantio direto) (MEDEIROS; SOARES; MENDES, 2005).

A época de semeadura 4 apresentou condições desfavoráveis ao cultivo na fase de diferenciação de primórdio floral no ano agrícola de 2008/09 (Figura 4). Nos demais anos, esta época evidenciou-se favorável ao cultivo, com maior disponibilidade hídrica nos períodos de maior exigência. Tais variações são normais, tendo em vista que para a realização de um zoneamento de risco climático se utiliza uma série de dados históricos de 15 anos (MAPA, 2012).

Os anos agrícolas de 2007/08 e 2008/2009
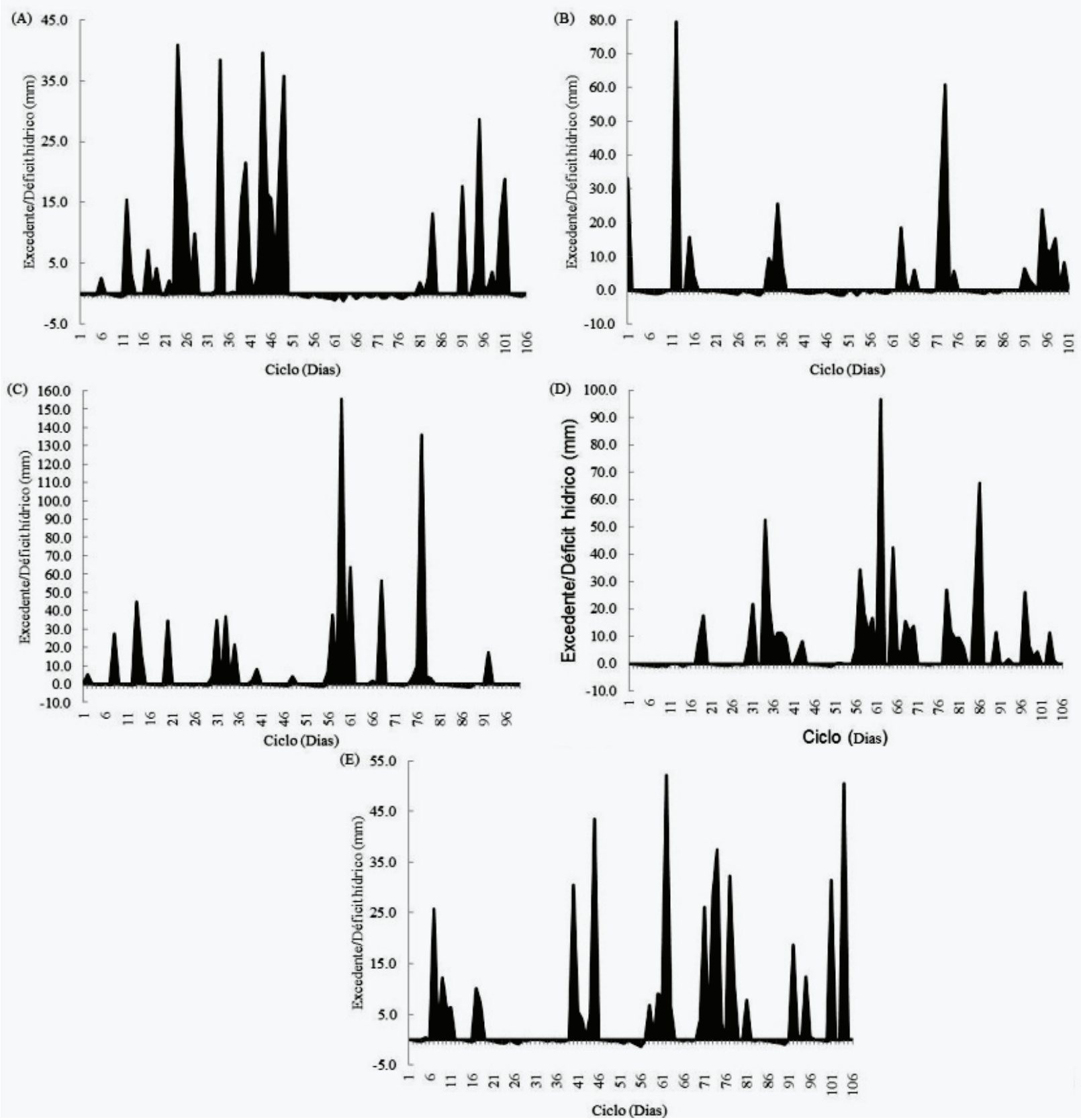

Figura 5. Balanço hídrico diário do município de Tangará da Serra - MT, dos anos agrícolas 2007/08 (A), 2008/09 (B), 2009/10 (C), 2010/11 (D) 2011/12 (E) na quinta época de semeadura (15 de dezembro). 
apresentaram deficiência hídrica para as fases de emergência e diferenciação de primórdio floral quando se analisou a época de semeadura 5 (15 de dezembro) (Figura 5). Nos demais anos analisados, o extrato do balanço hídrico diário apresentou condições favoráveis ao cultivo, sendo caracterizado por excedentes hídricos nas fases de diferenciação do primórdio floral e floração.
A época de semeadura 6 (31 de dezembro), apresentou maior uniformidade na distribuição das chuvas, especialmente na fase reprodutiva e nos dois últimos anos analisados (2010/11 e 2011/12) (Figura 6). Na fase de emergência, apenas o ano de 2008/09 apresentou déficit hídrico entre os anos analisados. Esta característica é muito favorável ao cultivo nesta época que, segundo Yoshida e
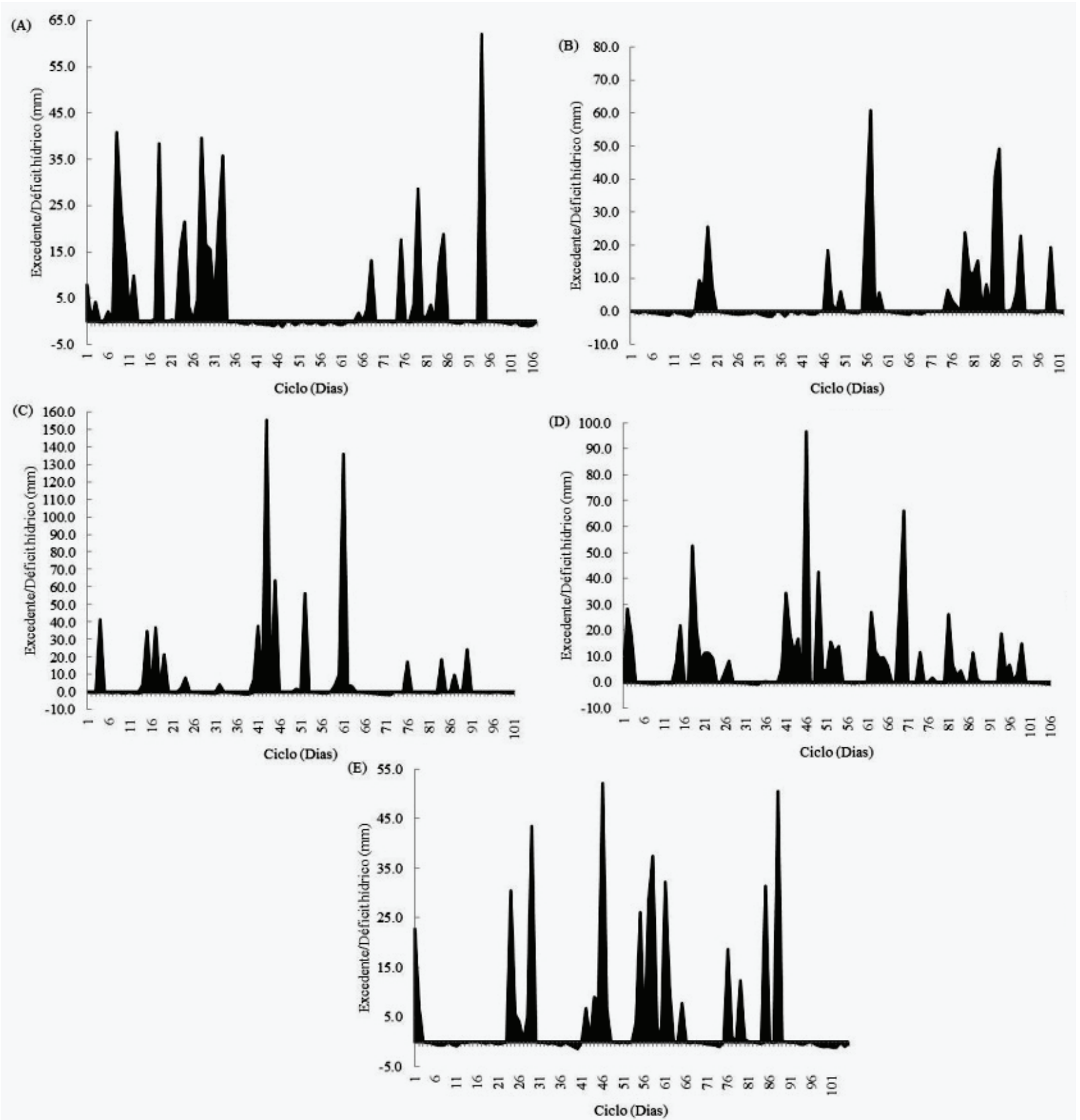

Figura 6. Balanço hídrico diário do município de Tangará da Serra - MT, dos anos agrícolas 2007/08 (A), 2008/09 (B), 2009/10 (C), 2010/11 (D) 2011/12 (E) na sexta época de semeadura (31 de dezembro). 
Quadro 3. Aptidão hídrica decendial da cultura do arroz, nos últimos cinco anos agrícolas (2007/2008 a 2011/2012), para seis épocas de semeadura, no município de Tangará da Serra, MT

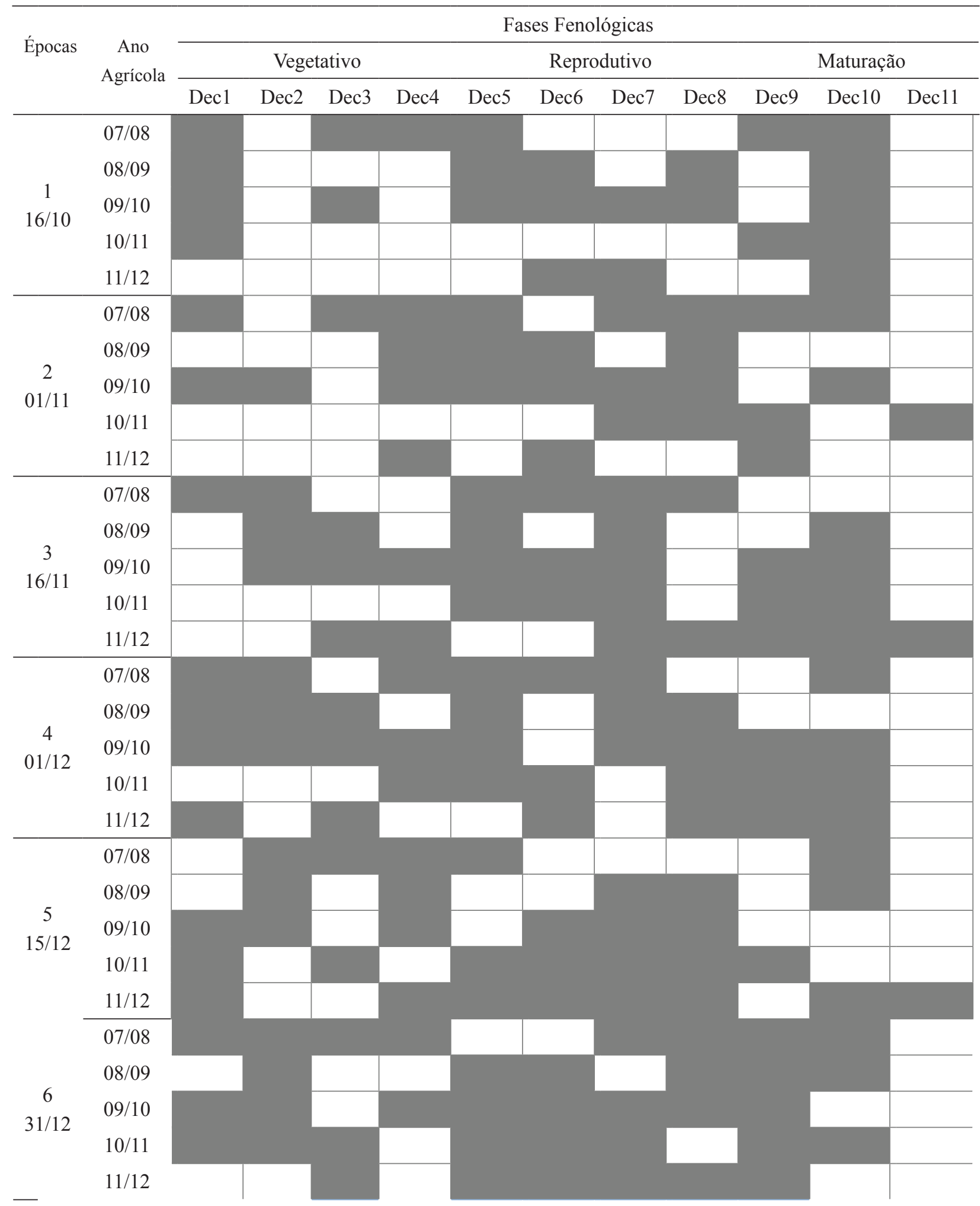

Decêndios com disponibilidade hídrica satisfatória.

Decêndios com deficiência hídrica para a cultura. 
Parao (1976) e Silva et al. (2009), a deficiência ocorrida próxima ao florescimento pode causar mais de $62 \%$ de esterilidade de espiguetas, afetando negativamente a formação de grãos e a produtividade do arroz.

Verifica-se no Quadro 3 que, em cultivo de sequeiro, a cultura do arroz fica exposta a ocorrência de déficit hídrico principalmente na fase reprodutiva, fase esta em que a cultura necessita de maior disponibilidade hídrica, sendo que para os demais estádios de desenvolvimento, somente foram registradas restrições hídricas para a época de semeadura 1 (2008/09 e 2011/12) e 3 (2007/08). Analisando o estádio de desenvolvimento E/R4, verifica-se como épocas mais favoráveis a 5 e 6 (15 de dezembro e 31 de dezembro).

De maneira geral, todos os anos em estudo apresentaram períodos de déficit hídrico em algum estádio de desenvolvimento da cultura. Variações atípicas no comportamento do regime pluviométrico são registradas ao longo dos anos, e em alguns casos são influenciadas por fenômenos naturais como o El Niño e a La Niña, que são registrados com o passar dos anos (CPTEC, 2012), e que ocorreram nos anos de 2009/2010 e 2007/2008, respectivamente, ocasionando influência no clima regional e global, através da mudança dos padrões dos ventos, afetando principalmente regiões tropicais e de latitudes médias (BERLATO; FARENZENA; FONTANA, 2005; MINUZZI, 2007; STRECK, 2008).

\section{CONCLUSÕES}

- As épocas de semeadura que apresentaram as melhores condições ao cultivo do arroz foram as épocas 5 ( 15 de dezembro) e 6 ( 31 de dezembro);

- Os maiores valores de precipitação foram registrados nas três últimas épocas de semeadura, na qual os anos agrícolas de 2009/2010 e 2010/2011 apresentaram os maiores valores de precipitação em todas as épocas de semeadura, com 1052,11 e 888,26 $\mathrm{mm}$, respectivamente;

- A média de duração de ciclo para as seis épocas de semeadura dos últimos anos agrícolas
(2007/2008 a 2011/2012) foram de 50 dias para E/R1, 78 dias em E/R4 e 103 dias para $\mathrm{E} / \mathrm{MC}$;

- Semeaduras mais tardias, como a época 5 e 6 , aumentam a duração total do ciclo, e o número de dias para a floração.

\section{REFERÊNCIAS BIBLIOGRÁFICAS}

BERLATO, M.A.; FARENZENA, H. FONTANA, D.C. Associação entre El Niño Oscilação Sul e a produtividade do milho no Estado do Rio Grande do Sul. Pesquisa Agropecuária Brasileira, Brasília, v.40, n.5, p.423-432, 2005.

BISCARO, G.A. Meteorologia agrícola básica. Cassilândia: Gráfica e editora União, 2007, 87p.

BRUNINI, O. et al. Eficiência do uso da água por cultivares de arroz em duas densidades de plantio. Bragantia, Campinas, v.40, n.1, p.135-42, 1981.

CARVALHO JÚNIOR, A.G. Efeito da adubação potássica em cultivares de arroz (Oryza sativa L.) de sequeiro sob déficit hídrico, em solos sob cerrado. 1987. 165f. Dissertação (Mestrado em Fitotecnia) - Escola Superior de Agricultura de Lavras, Lavras, 1987.

CENTRO INTEGRADO DE INFORMAÇÕES AGROMETEOROLÓGICAS - CIIAGRO. Zoneamento macro - aptidão ecológica da cultura do arroz, 2009. Disponível em: < http:// www.ciiagro.sp.gov.br/znmt_macro_5.html>. Acesso em: 02 out. 2012.

\section{CENTRO DE PREVISÃO E ESTUDOS} CLIMÁTICOS - CPTEC. El Niño e La Niña. São José dos Campos, CPTEC, 2012. Disponível em: $<$ http://enos.cptec.inpe.br/>. Acesso em: 02 out. 2012.

CRUSCIOL, C.A.C. et al. Manejo de irrigação por aspersão com base no "kc" e adubação mineral na cultura de arroz de terras altas. Bragantia, Campinas, v.62, n.3, p.465-475, 2003.

FARIA, R.T. et al. CLIMA - Programa computacional para organização e análise de dados 
meteorológicos. Revista Engenharia Agrícola, Jaboticabal, v.23, n.2, p.372-387, 2003.

FENNER, W. et al. Adaptabilidade agroclimática da cultura do arroz para a região de Tangará da Serra - MT. In: CONGRESSO DE INICIAÇÃO CIENTÍFICA, CÁCERES - MT, 4, 2011, Cáceres. Anais... Cáceres/MT: Pró-Reitoria de Pesquisa e Pós-Graduação - PRPPG, 2011. Vol.7 (2011). 1 CD-ROM 2178-7492.

HEINEMANN, A.B. Caracterização dos padrões de estresse hídrico para a cultura do arroz (Ciclo curto e médio) no Estado de Goiás e suas consequências para o melhoramento genético. Ciência e Agrotecnologia, Lavras, v.34, n.1, p.29-36, 2010.

HEINEMANN, A.B.; STONE, L.F. Efeito da deficiência hídrica no desenvolvimento e rendimento de quatro cultivares de arroz de terras altas. Pesquisa Agropecuária Tropical, Goiânia, v.39. n.2, p.134-139, 2009.

INSTITUTO BRASILEIRO DE GEOGRAFIA E ESTATÍSTICA-IBGE. Levantamento sistemático da produção agrícola, Rio de Janeiro, IBGE, 2012. LAGO, I.; STRECK, N.A.; CARVALHO, M.P.; FAGUNDES, L.K.; MOIANO DE PAULA, G.; LOPES, S.J. Estimativa da temperatura base do subperíodo emergência - diferenciação da panícula em arroz cultivado e arroz vermelho. Revista Ceres, Viçosa, v.1, n.1, p.23-30 2009.

LORENÇONI, R.; DOURADO NETO, D.; HEINEMANN, A.B. Calibração e avaliação do modelo ORYZA-APSIM para o arroz de terras altas no Brasil. Revista Ciência Agronômica, Fortaleza, v.41, n.4, p.605-613, 2010.

MARINI, P.; MORAES, C.L.; MARINI, N.; MUNT DE MORAES, D.; AMARANTE, L. Alterações fisiológicas e bioquímicas em sementes de arroz submetidas ao estresse térmico. Revista Ciência Agronômica, Fortaleza, v.43, n.4, p.722-730, 2012.

MEDEIROS, R.D.; SOARES, A.G.; MENDES, R. Efeitos da compactação do solo e do manejo da água sobre os componentes de produção e a produtividade de grãos de arroz. Revista Ciência e Agrotecnologia, Lavras, v.29, n.5, p.960-967, 2005.

MINISTÉRIO DA AGRICULTURA, PECUÁRIA E ABASTECIMENTO - MAPA. Zoneamento Agrícola de Risco Climático da cultura do arroz de sequeiro no Estado de Mato Grosso, ano-safra 2011/12. Brasília. Disponível em: <http://www. agrolink.com.br/culturas/arroz/arquivos/zoneamento_ mt_arroz.pdf $>$. Acesso em: 01 de out. 2012.

MINUZZI, R.B.; SEDIYAMA, G.C.; COSTA, J.N.; VIANELLO, R. L. Influência da La Niña na estação chuvosa da região sudeste do Brasil. Revista brasileira de Meteorologia, São José dos Campos, v.22, n.3, p.345-353, 2007.

NUNES, E.L.; AMORIM, R.C.F.; SOUZA, W.G.; RIBEIRO, A.; SENNA, M.C. A.; LEAL, B.G. Zoneamento agroclimático da cultura do café para a bacia do Rio Doce. Revista Brasileira de Meteorologia, São José dos Campos v.22, n.3, p.297-302, 2007.

PEREIRA, A.P. Simplificando o balanço hídrico de Thornthwaite-Mather. Bragantia, Campinas, v.64, n.2, p.311-313, 2005.

PIRES, R.C.M. ARRUDA, F.B.; SAKAI, E.; CALHEIROS, R.O.; BRUNINI, O. Agricultura irrigada. Revista Tecnologia e Inovação Agropecuária, São Paulo, v.1, n.1, p.98-110, 2008.

RODRIGUES, R.A.F.; SORATTO, R.P.; ARF, O. Manejo de água em arroz de terras altas no sistema de plantio direto, usando o tanque classe A. Revista Engenharia Agrícola, Jaboticabal, v.24, n.3, p.546-556, 2004.

ROLIM, G.S.; SENTELHAS, P.C.; BARBIERI, V. Planilhas no ambiente EXCEL para os cálculos de balanços hídricos: normal, sequencial, de cultura e de produtividade real e potencial. Revista Brasileira de Agrometeorologia, Campinas, v.6, n.1, p.133-137, 1998.

SILVA, E.A. SORATTO, R.P.; ADRIANO, E.; BISCARO, G.A. Avaliação de cultivares de arroz de terras altas sob condições de sequeiro 
em Cassilândia, MS. Ciência e Agrotecnologia, Lavras, v.33, n.1, p.298-304, 2009.

SILVA, S.C.; ASSAD, E.D. Zoneamento de riscos climáticos para o arroz de sequeiro nos estados de Goiás, Mato Grosso, Mato Grosso do Sul, Minas Gerais, Tocantins e Bahia. Revista Brasileira de Agrometeorologia, Campinas, v.9, n.3, p.536543, 2001.

STEINMETZ,S.;FAGUNDES,P.R.R.;MAGALHÃES JUNIOR, A.M.; SCIVITTARO, W.B.; DEIBLER, A.N.; ULGUIM, A.R.; NOBRE, F.L.L.; PINTANEL, J.B.A.; OLIVEIRA, J.G.; SCHNEIDER, A.B. Soma térmica e número de dias para atingir os principais estádios de desenvolvimento de 16 cultivares de arroz irrigado. Boletim de Pesquisa e Desenvolvimento, v.1, n.89, p.12-28, 2009.

STONE, L.F. Produtividade e utilização do nitrogênio pelo arroz (Oryza sativa $L_{\text {.) }}$ : efeito de deficiência hídrica, cultivares e vermiculita. 1982. 200f. Tese (Doutorado em Nutrição de Plantas) - Universidade de São Paulo, Escola Superior de Agricultura Luiz de Queiroz, Piracicaba, 1982.

STONE, L.F.; SILVEIRA, P.M. da. Arroz irrigado por aspersão. Santo Antônio de Goiás: Empresa Brasileira de Pesquisa Agropecuária - EMBRAPA, 2004. 5p. (Circular técnica, 64).
STRECK, N.A. et al. Duração do ciclo de desenvolvimento de cultivares de arroz em função da emissão de folhas no colmo principal, Ciência Rural, Santa Maria, v.36, n.4, p.1086-1093, 2006.

STRECK, N.A. et al. O fenômeno El Niño Oscilação Sul e a variabilidade interanual da evaporação do Tanque Classe A e da umidade relativa do ar em Santa Maria, RS. Ciência Rural, Santa Maria, v.38, n.5, p.1452-1455, 2008.

THORNTHWAITE, C.W.; MATHER, J.R. The water balance: publications in climatology. New Jersey: Drexel Institute of Technology, 1955. 104p. WREGE, M.S.; CARAMORI, P.H.; LUIS, S.L.G.; COLASANTE, O.; FUKOSHIMA, M.T.; ABUD, N.S. Determinação das melhores épocas de semeadura do arroz de sequeiro, Oryza sativa, no Estado do Paraná. Acta Scientiarum, Maringá, v.23, n.5, p.1179-1183, 2001.

XUE, Q.; WEISS, A.; BAENZIGER, P.S. Predicting leaf appearance in field-grown winter wheat: evaluating linear and non-linear models. Ecological Modelling, v.175, n.1, p.261-270, 2004.

YOSHIDA, S. Fundamentals of Rice crop science. Los Baños in: IRRI, 1981, 65-109p.

YOSHIDA, S.; PARAO, F.T. Climatic influence on yield components of lowland rice in the tropics. In: SYMPOSIUM ON CLIMATE \& RICE, 1974, Los Baños. Proceedings. Los Baños: IRRI, 1976. p.471-494. 